\title{
Numerical Investigation of Structural Behavior Of Fiber Reinforced Polymers Filled Sandwich Panels
}

\author{
Abubaker Sami DHEYAB \\ Research Scholar, Department of Civil Engineering \\ University of Gaziantep, Gaziantep, Turkey \\ Mahmood Hunar DHEYAALDIN \\ Research Scholar, Department of Civil Engineering \\ University of Gaziantep, Gaziantep, Turkey \\ Prof. Dr. Mustafa ÖZAKÇA \\ Professor, Department of Civil Engineering \\ University of Gaziantep, Gaziantep, Turkey
}

\begin{abstract}
This paper presents the numerical study of behavior of the sandwich panels, which consists of glass fiber reinforced polymer skins, and a polyurethane foam core and the sandwich panels, which contains glass fiber reinforced polymer U profile by using the ANSYS APDL program. The behavior of these panels was examined under 4 point load tests and the extent to which the numerical results were compared with the experimental results. Also, we studied the thickness of the skins of the sandwich panel as well as the effect of changing the type of core by using honeycomb core and study the effect of skins type and thickness by using carbon fiber reinforced plastic and aluminum in parametric study. Finite element analysis have given accurate results of the behavior of the sandwich panels under the loads.
\end{abstract}

Keywords - Sandwich panels, Glass fiber reinforced polymer Skins, Carbon fiber reinforced plastic skins, Finite Element, Composite materials, Polyurethane Foam core, Honeycomb core.

\section{INTRODUCTION}

Sandwich panels are lightweight construction systems of high strength-to-weight proportion. A typical sandwich panel consists of a low-density core material with two thin sheet faces. The skins have a relatively high stiffness and high tensile strength, assuring the panel's flexural capacity, while the low-density core material provides appropriate thermal insulating properties and might offer some shear resistance. The structural behavior of a sandwich panel strongly depends on the geometry, arrangement and properties of its components [1]. The using sandwich panels has been proved in several structural applications such as cladding facades, roofing and walls [2]. The Fiber reinforced polymer material has been accepted as an alternative construction material for several civil engineering applications. The challenge for many of the current research efforts is to improve the structural efficiency, performance and durability of the structural components built with these materials to match the load demands of civil engineering infrastructure and transportation applications [3]. The use of Glass Fiber Reinforced Polymer (GFRP) composites in structural application is increasing due to several advantages, including primarily durability against environmental exposure and high strength-to-weight ratio [4].

The glass is the most widely used fiber, because of the combination of low cost, corrosion resistance, and in many cases efficient manufacturing potential. It has relatively low stiffness, high elongation, and moderate strength and weight, and generally lower cost relative to other composites [5].

The skins take compressive and tensile loads and the core transfers shear loads between the faces while providing high bending stiffness. Stabilizes the skins against buckling and wrinkling, and provides thermal and acoustic isolation [2,6]. An important advantage for polyurethane foam: lower material and labor costs, higher impact 
resistance and damping, compatible material to the polyurethane resin, which aids in the infusion process and bonding with the face sheets [7].

\section{BACKGROUND}

Researchers have studied the properties and behavior of sandwich panel structure through experimental studies or numerical studies to better understand their behavior under different loads and conditions.

Russo and Zuccarello [8] worked on a systematic experimental and numerical study of such composites as well as the individual materials constituting skins and cores has been per-formed. The results of accurate nonlinear numerical simulations are also presented and used to develop reliable failure criteria.

Correia et al [9] studied on experimental investigations on the mechanical behavior of composite sandwich panels, taking into account their possible structural use in civil engineering applications, such as building floors or footbridge decks.

Mostafa \& Shankar [10] studied on to the improvement of the shear performance of the composite sandwich panels constituted by GFRP laminate skin with PU foam core incorporated with chopped strand glass fibers shear keys. Parametric investigation using Finite Element (FE) analysis to select the most optimum diameter of the shear key taking into consideration the material nonlinearity and the interaction between all the surfaces is performed. Furthermore, the model has the ability to prophesy the failure mode and the shear strength of the sandwich panel.

Correia et al [11] worked on experimental and numerical investigations on the mechanical behavior of sandwich panels with GFRP skins. The performance of two different core materials - rigid plastic polyurethane (PU) foam and polypropylene (PP) honeycomb - and the effect of using lateral GFRP ribs along the longitudinal edges of the panels were investigated. Results of experiments are compared with predictions obtained from analytical and numerical models, allowing their calibration and validation.

Tuwair et al. [7] studied on evaluation of three potential core alternatives for GFRP foam-core sandwich panels. The proposed system could reduce the initial costs and Difficulties in manufacturing while improving the system performance. Three different polyurethane foam configurations were considered for the core, and the most suitable system was recommended for further prototyping. (High-density polyurethane foam, low-density polyurethane foam and low-density polyurethane foam utilizing GFRP web layers), a FE model was developed using for investigating of structural behavior. And comparison between experimental results indicate its suitability for parametric analysis of panels and their design.

In this paper, the nonlinear properties of the sandwich plate, which consists of two skins of GFRP and PU foam core, were studied using numerical design and analysis by use ANSYS APDL software. The study was divided into two parts: the first is verification phase; numerical simulations were carried out based on experimental data and mechanical properties evaluated by Abdolpour et al.[2] and compared numerical results with experimental results. In this section, two types of sandwich plate were modeled: The first small scale of sandwich panels, the second small scale of sandwich panels with GFRP U Profile.The second phase is parametric study, in this phase was studied of the effect of the thickness and type of material for skins type of core.

\section{Finite ELEMENT MODEL}

Small scale of sandwich panel was modeled by use ANSYS APDL software. The modeling of shapes by nonlinear three-dimensional FE analysis. The numerical simulation enabled the identification of the distribution of stresses in the components and the understanding of the mechanism of transfer of loads as well as the representation of how to connect the components in the composite materials. Several elements were used in this study and where skins and GFRP profile were represented using 3D solid element SOLID185. It has eight nodes having three degrees of freedom at each node translations in the nodal $x, y$, and $z$ directions. The element has plasticity, hyperelasticity, stress stiffening, creep, large deflection, and large strain capabilities [12]. 3D SOLID45 element was used to model the PU foam core. Which is defined by eight nodes having three degrees of freedom at each node: translations the nodal $x, y$ and $z$ directions. The element SOLID45 has plasticity, creep, swelling, stress stiffening, large deflection and large strain capabilities [13]. GFRP honeycomb core were represented by using 3D solid shell element SOLSH190. It has eight-node connectivity with three degrees of freedom at each node: translations in the nodal $x, y$, and $z$ directions.

Volume 8 Issue 3 June 2017

ISSN: 2319-1058 
The element has plasticity, hyperelasticity, stress stiffening, creep, large deflection, and large strain capabilities. It also has mixed displacement versus load formulation capability for simulating deformations of nearly incompressible elastoplastic materials, and fully incompressible hyperelastic materials [12]. The sandwich panels consists of different materials (skin and core) so the binding process between them is required to be used contact element CONTACT175. The element is applicable to 2-D or 3-D structural and coupled field contact analyses. This element is located on the surfaces of solid, beam, and shell elements. and The contact elements TAGRET170 themselves overlay the solid, shell, or line elements describing the boundary of a deformable body and are potentially in contact with the target surface [12].

\section{VERIFICATION PHASE}

At this stage, two models were simulated:

A. FE analysis of small scale of sandwich panels without GFRP U profile:

The model is designed for the sandwich panel without GFRP U profile (PG5), which is made of two skins, each with a thickness of $5 \mathrm{~mm}$ and a length of $950 \mathrm{~mm}$ and a width of $350 \mathrm{~mm}$ and between the two skins there is a core of foam material $60 \mathrm{~mm}$ thickness. The clear span was $900 \mathrm{~mm}$ and shear span was $300 \mathrm{~mm}$. GFRP skin was defined as linear-elastic orthotropic material. The mechanical properties for GFRP skin: elastic modulus $\mathrm{E}_{\mathrm{x}}=9.6 \mathrm{GPa}, \mathrm{E}_{\mathrm{y}}=10.3$ $\mathrm{GPa}$, Poisson ratio 0.3, ultimate stress $117 \mathrm{MPa}$. PU foam material for the core is defined as isotropic material. PU foam properties: elastic modulus $\mathrm{E}_{\mathrm{x}}=9.1 \mathrm{MPa}$, Poisson ratio $v=0.3$, yield stress $0.3 \mathrm{MPa}$. Applied loads were defined as force on nodes at the top surface of skin. For the supports, have been defined as displacement of nodes on bottom skin. The typical FE models used for the sandwich panel and sandwich panel without GFRP U profile for 4 point load test is shown in Fig. 1.

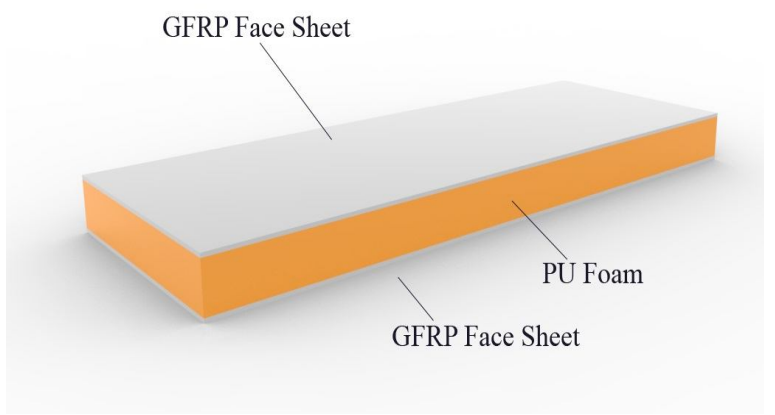

(a)

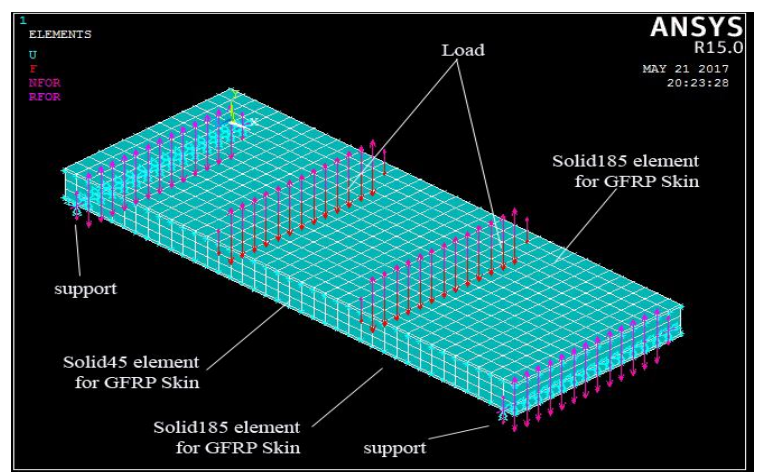

(b)

Figure 1. (a) Schematic illustration for small scale of sandwich panels without GFRP U profile. (b) FE Model for small scale of sandwich panels without GFRP U profile (PG5).

By comparing the numerical results obtained using the ANSYS program and the experimental results done by Abdolpour et al. [2] shown in Table 1. It is found that they are very close and acceptable. Fig. 2.a shows the corresponding load-deflection curve in midspan provided by the non-linear FEM analysis, along with that obtained experimentally. It is shown that a good agreement between numerical and experimental results. The vertical displacement shown in Fig. 2.b can be seen in the direction of the Y axis obtained from the FE model where the maximum value of deflection was $14.53 \mathrm{~mm}$ in midspan at ultimate load $7.7938 \mathrm{kN}$.

Table 1

Comparison between experimental and numerical FEM results for small scale of sandwich panels without U profile (PG5).

\begin{tabular}{lll}
\hline & FE Result & Experimental Result \\
\hline Ultimate Load (kN) & 7.7938 & 7.27 \\
$\begin{array}{l}\text { Ultimate Deflection in } \\
\text { midspan (mm) }\end{array}$ & 14.5376 & 13.59 \\
Ultimate Stress (MPa) & 10.84 & 9.58
\end{tabular}




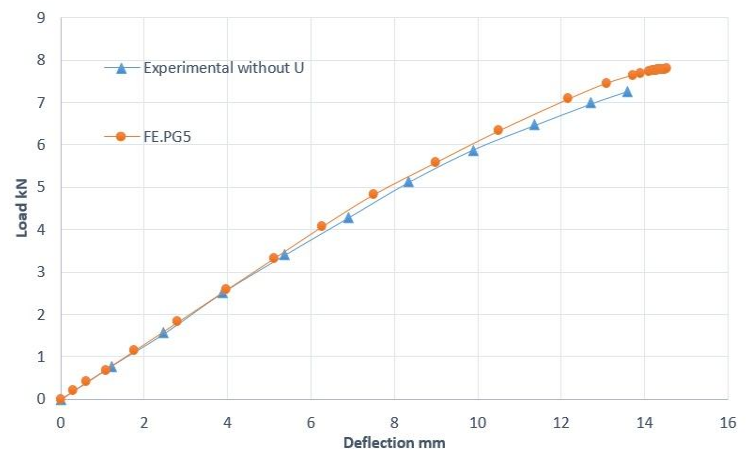

(a)

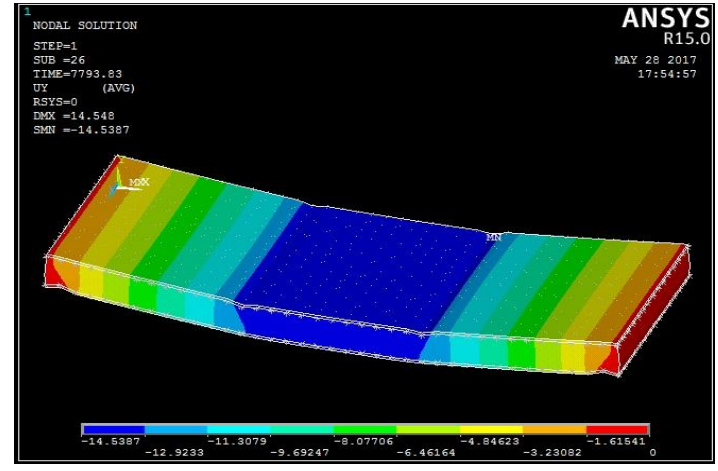

(b)

Figure 2. (a) The comparison between numerical and experimental load-midspan deflection curves. (b) Deformed shape for the FE model for sandwich panels without U (PG5) (deflections, in mm).

\section{B. FE Analysis of small scale of sandwich panels with U profile:-}

The numerical modeling of a new shape of the sandwich panels with GFRP U profile (PGU5) as shown in Fig.3 is similar to that of the experimental study [2]. The sandwich panels with GFRP U profile consisted of two layers of 5 mm GFRP skins, with a thickness of $60 \mathrm{~mm}$ for PU foam core. The sides are added GFRP U profile as shown in Fig 3.a. Materials: GFRP skin is defined as linear-elastic orthotropic material. The mechanical properties for GFRP skins: elastic modulus $\mathrm{E}_{\mathrm{x}}=9.6 \mathrm{GPa}, \mathrm{E}_{\mathrm{y}}=10.3 \mathrm{GPa}$, Poisson ratio $v=0.3$, ultimate stress $117 \mathrm{MPa}$. PU foam material for the core is defined as isotropic material. PU foam properties: elastic modulus $\mathrm{E}_{\mathrm{x}}=9.1 \mathrm{MPa}$, Poisson ratio $v=0.3$, yield stress 0.3 MPa. GFRP U profile has been defined as linear-elastic orthotropic material. It carries the following properties: elastic modulus $\mathrm{E}_{\mathrm{x}}=28 \mathrm{GPa}, \mathrm{E}_{\mathrm{y}}=13 \mathrm{GPa}$, Poisson ratio 0.3, ultimate stress $415 \mathrm{MPa}$. It was modeled according to the paragraph mentioned in part FE model. Loads were defined as force on nodes at the top surface of skin. The supports are represented displacement of nodes on inside GFRP U profile as illustrated in Fig. 3.b. The clear span between the supports is $1150 \mathrm{~mm}$ and shear span $300 \mathrm{~mm}$.

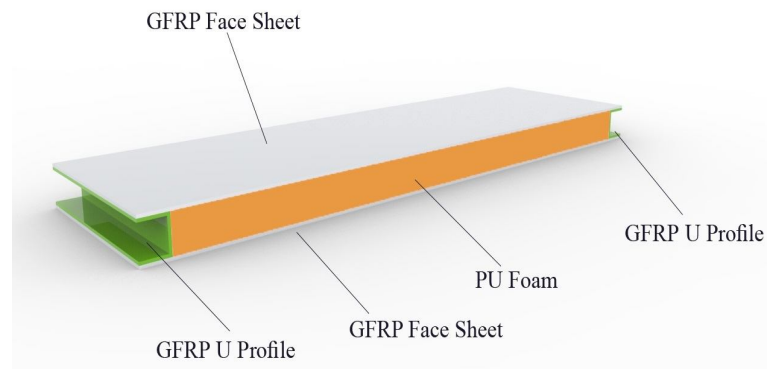

(a)

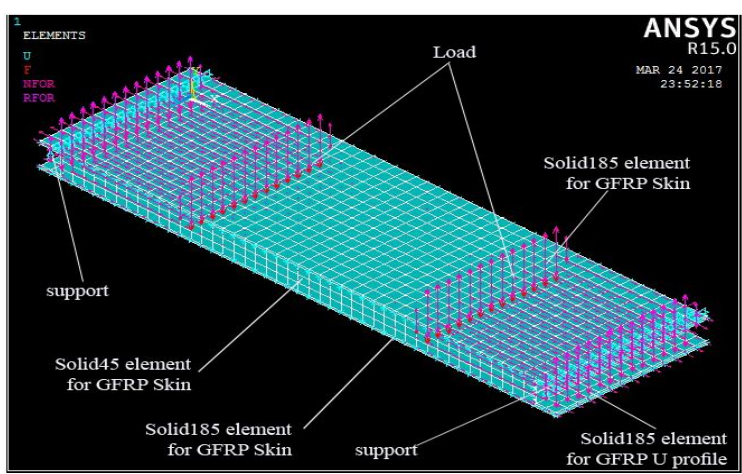

(b)

Figure 3. (a) Schematic illustration for small scale of sandwich panels with GFRP U profile. (b) FE Model for Small scale of Sandwich panels with GFRP U profile (PUG5).

The results of FE analysis are very acceptable after comparing them with the experimental results, Which is evaluated by Abdolpour et al [2]. Table 2 shows the comparison. The relationship between the load and deflection illustrated in Fig.4.a can be observed by comparing diagram for load -deflection curve that the variation is very small and acceptable when ultimate load $7.473 \mathrm{kN}$ the deflection $20.93 \mathrm{~mm}$ in $y$ direction. The behavior of the FE model for small scale of sandwich panels with GFRP U profile after failure load is shown in Fig 4.b.

Table 2

Comparison between experimental and numerical FEM results for small scale of sandwich panels with U profile (PUG5). 


\begin{tabular}{|c|c|c|}
\hline & FE Result & Experimental \\
\hline Ultimate Load (kN) & 7.473 & 7.18 \\
\hline $\begin{array}{l}\text { Ultimate Deflection in } \\
\text { midspan }(\mathrm{mm})\end{array}$ & 20.9311 & 20.01 \\
\hline Ultimate Stress (MPa) & 11.8 & 9.47 \\
\hline
\end{tabular}

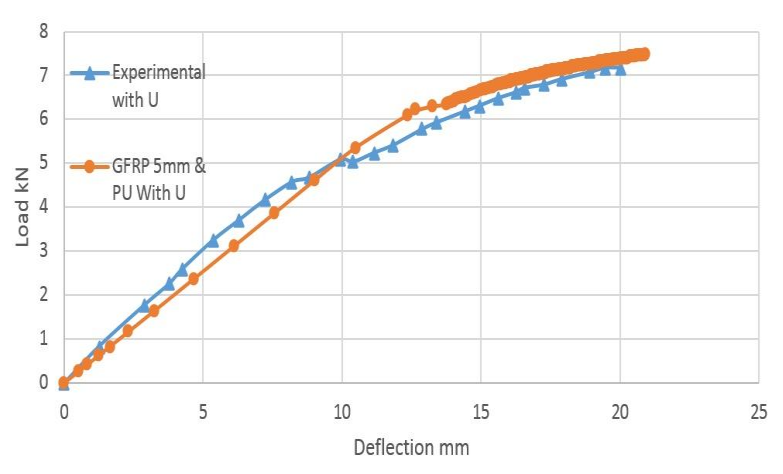

(a)

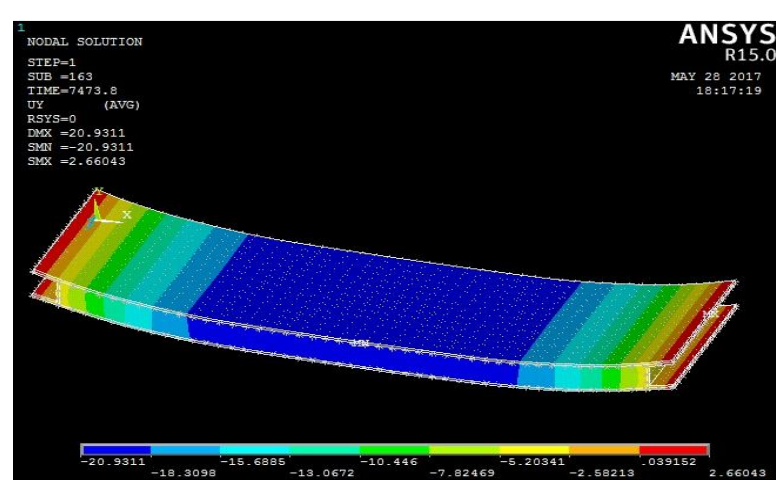

(b)

Figure 4. (a) The comparison between numerical and experimental load-midspan deflection curves. (b) Deformed shape for the FE model for sandwich panels with U (PUG5) (deflections, in mm).

\section{PARAMETRIC STUDY}

Through verification phase, we found the extent of convergence between the FE results and the experimental results of the two models that were modeled using the ANSYS program and to understand the behavior of the effect under the load effect. Therefore, a further study was conducted, which is a parametric study where the effect of the thickness of the skins on the work and efficiency of the sandwich panels was made simulation to 30 model. The models of the first group took the same properties of the materials mentioned in the verification study stage and the same dimensions, but the thickness of GFRP skins (top skin, bottom skin) changed the sandwich plate in this order (3, 7 and $9 \mathrm{~mm})$. For small scale of sandwich panels without GFRP U profile with deferent thickness $(3,7$ and $9 \mathrm{~mm})$ (PG3, PG7 and PG9) and small scale of sandwich panels with GFRP U profile with deferent thickness (3, 7 and 9 $\mathrm{mm}$ ) (PGU3, PGU7 and PGU9). The results for numerical analysis are listed in Table 3. The relationship between load and deflection for models (load-deflection curve) shown in Fig.6.a.

In the second group, Carbon Fiber Reinforced Plastics (CFRP) was used for skin with Polyurethane (PU) foam to core of sandwich panels. The mechanical properties of CFRP was evaluated by Rejab and Cantwell [14]: elastic modulus $\mathrm{E}_{\mathrm{x}}=48 \mathrm{GPa}, \mathrm{E}_{\mathrm{y}}=48 \mathrm{GPa}, \mathrm{E}_{\mathrm{z}}=1 \mathrm{GPa}$, Poisson ratio $v=0.1$, ultimate stress $550 \mathrm{MPa}$. CFRP skin was defined as linear-elastic orthotropic material. The effects of thickness of skins was studied for small scale of sandwich panels CFRP skin without U profile, models that differ in thickness of skin were simulated (3, 5, 7 and 9 mm) (PC3, PC5, PC7 and PC9). And the same procedure for small scale of sandwich (CFRP skin) with U profile skin were simulated $(3,5,7$, and $9 \mathrm{~mm}$ ) (PUC3, PUC5, PUC7, PUC9). The result is shown in Table3. Load-deflection curve in midspan illustrative in Fig.6.b.

Third group of parametric study is using aluminum as a skin for the sandwich panel, where the mechanical properties that were evaluated by Rejab and Cantwell [14]. The aluminum material was represented as Isotropic material: elastic modulus $\mathrm{E}_{\mathrm{x}}=70.6 \mathrm{GPa}$, Poisson ratio $v=0.3$, yield stress $164.7 \mathrm{MPa}$. The small scale of sandwich panels without $U$ profile was modeled with a different thickness of the skins (3, 5, 7, and 9 mm) (PA3, PA5, PA7, PA9). And also the small scale of sandwich panels with $U$ profile was modeled with a different thickness of the skins (3, 5, 7, and $9 \mathrm{~mm})$ (PUA3, PUA5, PUA7, PUA9). All results and the relationship between load-deflection curves are shown in Table 3 and Fig. 6.c respectively. 
To further understand the behavior of the sandwich panel core, in the fourth group, the PU foam core was changed by using GFRP honeycomb core. Fig. 5 shows the details of sandwich panels with GFRP honeycomb core. The thickness of GFRP skins were changed. Also divided into without U profile (PH3, PH5, PH7, and PH9) according thickness skins $(3,5,7$, and 9mm) and with U profile (PUH3, PUH5, PUH7, and PUH9). All results and the relationship between load-deflection curves are shown in Table 3 and Fig. 6.d respectively.

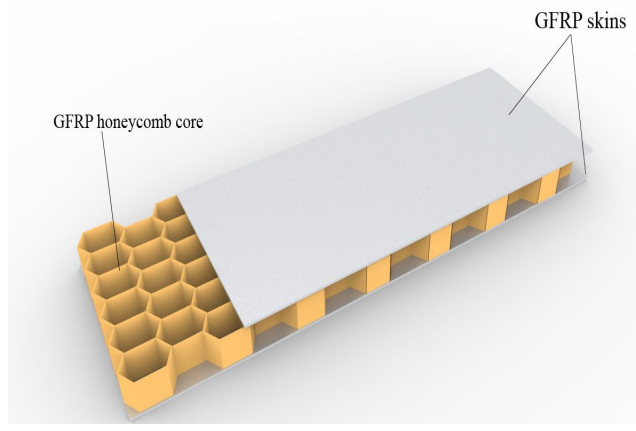

(a)

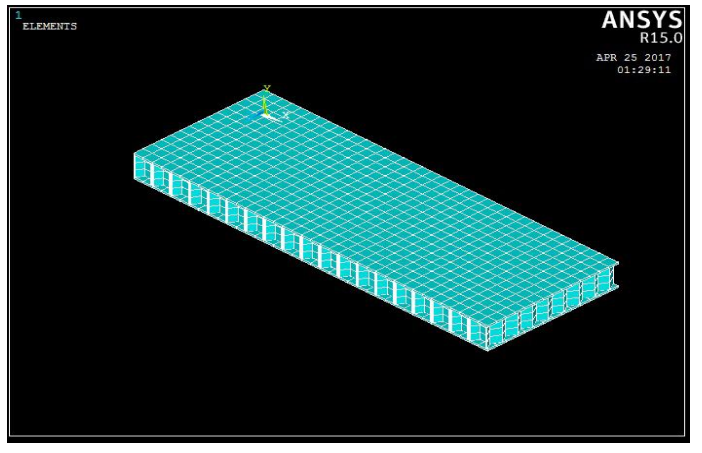

(b)

Figure 5. (a) Schematic illustration for small scale of sandwich panels with GFRP honeycomb core. (b) FE Model for Small scale of sandwich panels with GFRP honeycomb core.

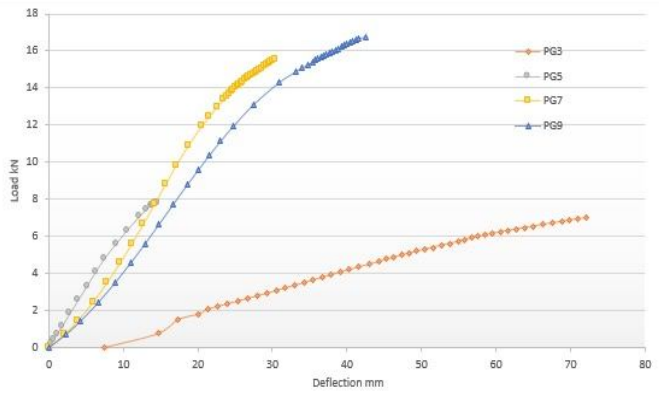

(a.1)

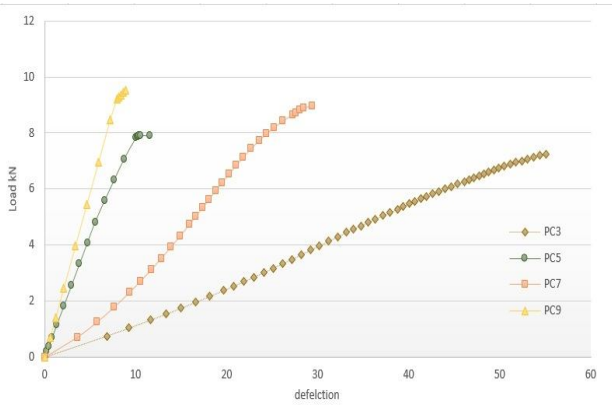

(b.1)

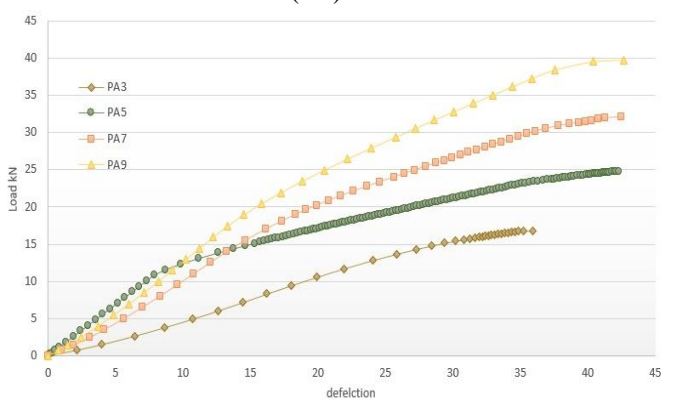

Volume 8 Issue 3 June 2017 (a)

(b)

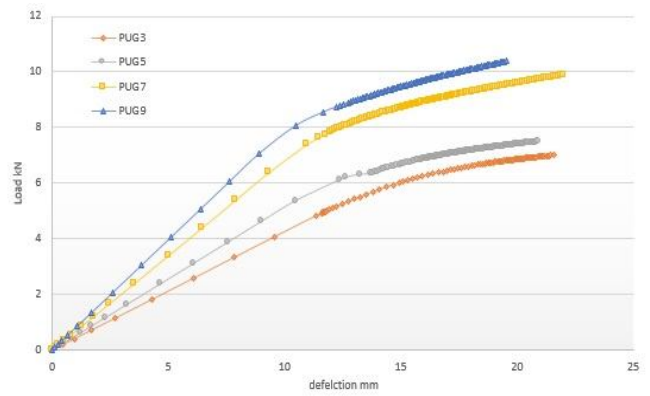

(a.2)

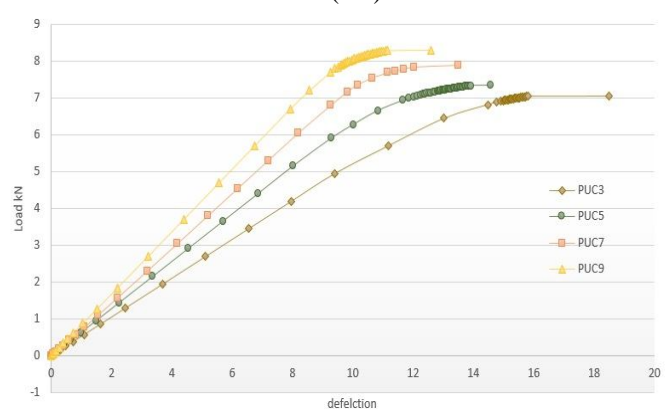

(b.2)

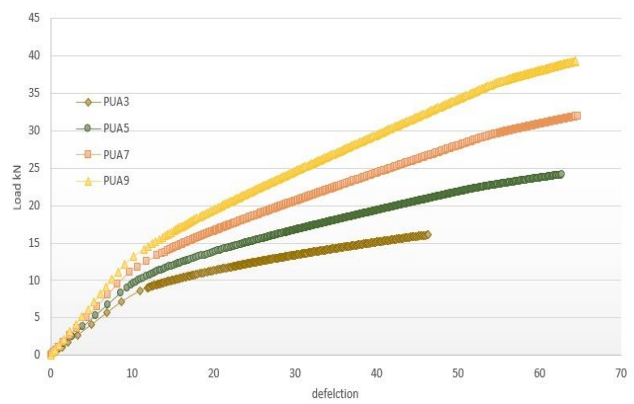


(c.1)

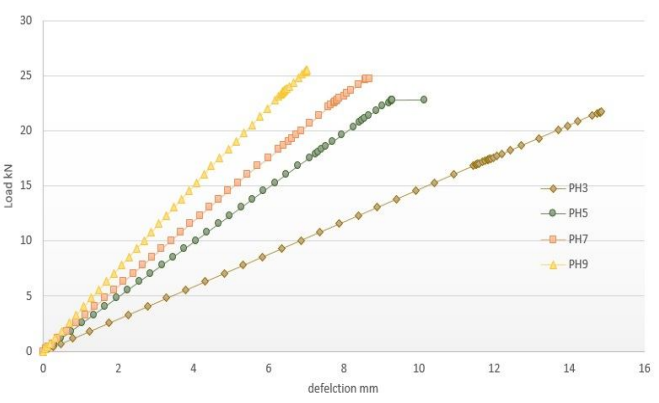

(d.1) (c)

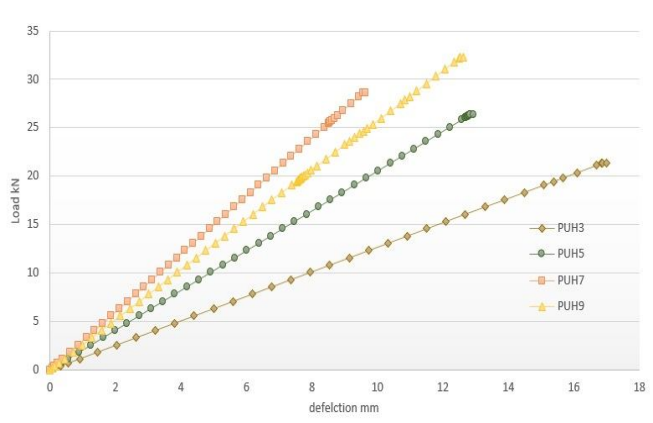

(d)

(d.2)

Figure 6. Load-deflection curves: ( a.1) GFRP skins without U, (a.2) GFRP skins with U, (b.1) CFRP skins without U, (b.2) CFRP skins with U, (c.1) aluminum skins without U, (c.2) aluminum skins with U, (d.1) GFRP skins \& honeycomb core without U, (d.2) GFRP skins \& honeycomb core with U.

Table 3

FEM results for all model in parametric study of small scale of sandwich panels.

\begin{tabular}{|c|c|c|c|c|}
\hline \multicolumn{2}{|c|}{ TYPE OF SANDWICH PANELS } & \multirow{2}{*}{$\begin{array}{c}\text { ULTIMATE } \\
\text { LOAD }(K N) \\
7.04\end{array}$} & \multirow{2}{*}{$\begin{array}{c}\text { DEFLECTION } \\
\text { IN MIDSPAN } \\
(\text { MM) } \\
72\end{array}$} & \multirow{2}{*}{$\begin{array}{c}\text { ULTIMATE STRESS } \\
\text { (MPA) } \\
26.269\end{array}$} \\
\hline GERP SKINS WITHOUT & PG3 & & & \\
\hline U PROFILE & $P G 7$ & 15.54 & 30.79 & 14.77 \\
\hline & $P G 9$ & 16.77 & 42.51 & 16.57 \\
\hline \multirow{3}{*}{$\begin{array}{c}\text { GFRP SKINS WITH U } \\
\text { PROFILE }\end{array}$} & PUG3 & 6.99 & 21.59 & 17.5 \\
\hline & PUG7 & 9.879 & 22 & 11.19 \\
\hline & $P U G 9$ & 10.38 & 19.529 & 9.88 \\
\hline \multirow{4}{*}{$\begin{array}{c}\text { CFRP SKINS WITHOUT } \\
\text { U PROFILE }\end{array}$} & PC3 & 7.25 & 55.7 & 60 \\
\hline & $P C 5$ & 7.9 & 11.59 & 14.88 \\
\hline & $P C 7$ & 8.969 & 29.4 & 37.4 \\
\hline & $P C 9$ & 9.52 & 8.911 & 20.8 \\
\hline \multirow{4}{*}{$\begin{array}{c}\text { CFRP SKINS WITH U } \\
\text { PROFILE }\end{array}$} & PUC3 & 7 & 18.4 & 37.9 \\
\hline & PUC5 & 7.334 & 14.56 & 29.6 \\
\hline & PUC7 & 7.89 & 13.94 & 14.7 \\
\hline & PUC9 & 8.3 & 12.58 & 13.23 \\
\hline \multirow{4}{*}{$\begin{array}{l}\text { ALUMINUM SKINS } \\
\text { WITH U PROFILE }\end{array}$} & $P A 3$ & 16.838 & 35.91 & 42.2 \\
\hline & PA5 & 24.82 & 42.3 & 55 \\
\hline & PA7 & 32 & 42.5 & 66.56 \\
\hline & PA9 & 39.79 & 42.67 & 73 \\
\hline \multirow{5}{*}{$\begin{array}{c}\text { ALUMINUM SKINS } \\
\text { WITHOUT U PROFILE }\end{array}$} & PUA3 & 16 & 46.33 & 40.5 \\
\hline & PUA5 & 24.1 & 62.7 & 53.48 \\
\hline & PUA7 & 31.9 & 64.67 & 63.59 \\
\hline & PUA9 & 39.26 & 64.72 & 72.9 \\
\hline & DU2 & 0175 & 15 & 16 \\
\hline
\end{tabular}




\section{RESULTS AND DisCUSSION}

The numerical analysis summary is given in Table 3 as well as Figure 6, which shows the extent of variance and convergence in the results. The first group, which was designed and composed of a surface of GFRP skins without U profile, Where the results varied according to the thickness of the skins (PG3, PG5, PG7, and PG9) was the ultimate load $(7,7.79,15.54$, and $16.77 \mathrm{kN})$ respectively, the stresses for them were $(26.26,10.84,14.77$, and $16.57 \mathrm{MPa})$ in order, but the deflection was $(72,14.5,30.97$, and $42.51 \mathrm{~mm})$ respectively. For different thickness of skins (PUG3, PUG5, PUG7, PUG9) of sandwich panels with U profile the results was: the ultimate load (6.99, 7.47, 9.87, and 10.38 $\mathrm{kN})$, ultimate stresses $(17.9,11.8,11.19$, and 9.88 Mpa), maximum deflection in midspan $(21.59,20.93,22$, and 19.5 $\mathrm{mm}$ ). The results can be observed when a type of skin material has been changed, such as CFRP without U profile (PC3, PC5, PC7, and PC9). Ultimate load (7.25, 7.9, 8.69, and 9.52 kN), stresses (60, 14.88, 37.4, and 20.8 MPa) and deflection in midspan $(55.79,11.5,29.4$, and $8.4 \mathrm{~mm})$. For CFRP skins of sandwich panels with U profile (PUC3, PUC5, PUC7, and PUC9). Ultimate load (7, 7.3, 7.8, and 8.3 kN), stresses (37.9, 29.6, 14.7, and 13.23 MPa) and deflection in midspan $(18.4,14.56,13.94$, and $12.58 \mathrm{~mm})$. It is possible to conclude that aluminum is best for skin material. From a curved observation between deformation and load, it has a turning point after which the failure occurs and the maximum load for aluminum skins without U profile (PA3, PA5, PA7, and PA9) (16.83, 24.82, 32, and $39.79 \mathrm{kN})$, stresses $(42.2,55,66.56$, and $73 \mathrm{MPa})$ and deflection in midspan $(35.91,42.3,42.5$, and $42.67 \mathrm{~mm})$. For aluminum skins of sandwich panels with U profile (PUA3, PUA5, PUA7, and PUA9). Ultimate load (16, 24.1, 31.9 , and $39.26 \mathrm{kN})$, stresses $(40.5,53.48,63.59$, and $72.9 \mathrm{MPa})$ and deflection in midspan $(46.33,62.7,64.47$, and $64.72 \mathrm{~mm}$ ). After studying the types of the sandwich panels it was concluded that the failure occurs in the core before the skins, the difference was evident in the loads as well as the stresses as well as the deformity After replacing the PU foam core to the new core (Honeycomb core) (PH3, PH5, PH7, and PH9) without U profile Ultimate load (21.75, 22.86, 24.77, and 25.52 kN), stresses (46, 29.8, 27.9, and 26.4 MPa) and deflection in midspan $(15,10.14,8.67$, and 7 $\mathrm{mm}$ ). For with U profile (PUH3, PUH5, PUH7, and PUH9) result was found ultimate load (21.36, 26.37, 28.66, and $32.3 \mathrm{kN})$, stresses $(46,35.8,25$, and $36 \mathrm{MPa})$ and deflection in midspan $(16.99,12.93,9.62$, and $12.62 \mathrm{~mm})$.

\section{CONCLUSION}

The study of the behavior for composite materials (sandwich panels) through FE analysis where proved the compatibility of numerical analysis with the experimental results and a few differences. the sandwich panels was failure occurs in the PU foam and to bear a little compressibility as well as little resistance to shear, the face sheets have a tensile strength and stress higher than PU foam. Either failure in the sandwich panel supported by $U$ profile where the failure occurs in the near part of the U profile because of shear and also in the contact area between the sandwich panels components (face sheets, core) or U profile. Through the parametric study found that the relationship between the thickness of skins and deflection is an inverse relationship as well as the relationship between thickness of skins and stress are inversely related with increasing the failure load value for sandwich panel. As for the change in skin material to CFRP, it was observed that the results to failure load and deflection remained the same but increased stress. In the case of change material of skins to aluminum increased the load of failure and stress and also the rate of deflection. In the case of change of PU foam to honeycomb core, it was found that the load of failure is increased and the stresses for the deformation

\section{REFERENCE}

[1] M. Mastali, I. B. Valente, and J. A. O. Barros, "Development of innovative hybrid sandwich panel slabs: Advanced numerical simulations and parametric studies," Compos. Struct., vol. 152, pp. 362-381, 2016.

[2] H. Abdolpour, J. Garzón-Roca, G. Escusa, J. M. Sena-Cruz, J. A. O. Barros, and I. B. Valente, "Development of a composite prototype with GFRP profiles and sandwich panels used as a floor module of an emergency house," Compos. Struct., vol. 153, pp. 81-95, 2016.

[3] G. Sopal, S. Rizkalla, and G. Solomon, "Performance of New 3D GFRP Sandwich Panels with Corrugated GFRP Sheets," 6th Internaional Conf. RFP Compos. Civ. Eng. CICE-6, pp. 1-8, 2012.

[4] H. Mathieson and A. Fam, "High cycle fatigue under reversed bending of sandwich panels with GFRP skins and polyurethane foam core," Compos. Struct., vol. 113, no. 1, pp. 31-39, 2014.

[5] R. p Praveen, "Prediction of Delamination in End Milling of GFRP Using ANSYS," vol. 6, pp. 39-46, 2013.

[6] N. Pokharel and M. M. Ã, "Finite element analysis and design of sandwich panels subject to local buckling effects," Thin-Walled Struct., vol. 42, no. 4, pp. 589-611, 2004.

[7] Tuwair H, Hopkins M, Volz J, ElGawady M, Mohamed M, Chandrashekhara K, and Birman V., "Evaluation of sandwich panels with various polyurethane foam-cores and ribs," Compos. Part B Eng., vol. 79, pp. 262-

Volume 8 Issue 3 June 2017 
276, 2015.

[8] A. Russo and B. Zuccarello, "Experimental and numerical evaluation of the mechanical behaviour of GFRP sandwich panels," Compos. Struct., vol. 81, no. 4, pp. 575-586, 2007.

[9] J. R. Correia, M. Garrido, J. a. Gonilha, F. a. Branco, and L. G. Reis, "GFRP sandwich panels with PU foam and PP honeycomb cores for civil engineering structural applications: Effects of introducing strengthening ribs,” Int. J. Struct. Integr., vol. 3, no. 2, pp. 127-147, 2012.

[10] A. Mostafa and K. Shankar, "In-Plane Shear Damage Prediction of Composite Sandwich Panel with Foam Core,” Appl. Mech. Mater., vol. 376, pp. 69-73, 2013.

[11] J. Ramôa Correia, F. Branco, I. Almeida, and J. A. Gonilha, "Structural behaviour of composite sandwich panels for civil engineering applications," Large Struct. Infrastructures Environ. Constrained Urban. Areas, pp. $1-8,2010$.

[12] ANSYS Inc., "ANSYS Mechanical APDL Element Reference," ANSYS Man., vol. 15, pp. 1377-1390, 2013.

[13] P. Sahoo and N. Ghosh, "Finite element contact analysis of fractal surfaces," J. Phys. D. Appl. Phys., vol. 40, no. 14, pp. 4245-4252, 2007.

[14] M. R. M. Rejab and W. J. Cantwell, "The mechanical behaviour of corrugated-core sandwich panels," Compos. Part B Eng., vol. 47, pp. 267-277, 2013. 